\title{
SIG, Teledetección y modelos basados en variables oceanográficas aplicados a la pesquería de la Pota (Dosidicus gigas) en Paita, 2010 - 2011
}

\section{GIS, Remote Sensing and prototype based in oceanographic variables applied to the fishery of the Humboldt squid (Dosidicus gigas) in Paita, 2010 - 2011}

\author{
Juan Tume ${ }^{1}$, Ronald Marcial ${ }^{2}$
}

http://dx.doi.org/10.21503/CienciayDesarrollo.2013.v16i2.03

\section{RESUMEN}

En este trabajo se presenta el resultado de la aplicación de los Sistemas de Información Geográfica (SIG), en el análisis de las variables oceanográficas temperatura y clorofila a, sobre la ubicación de las zonas de pesca. Se utiliza el SOFTWARE ARC GIS 9,2, en el se ha superpuesto las capas de temperatura clorofila a y capturas por parte de la embarcaciones artesanales que se dedican a la pesca de pota

Los resultados obtenidos nos demuestran que hay una correlación entre la ubicación de las zonas de pesca y la distribución de la temperatura superficial del mar y además con la concentración de clorofila a. Se determinó el rango de ubicación de temperatura entre 16 y $23^{\circ} \mathrm{C}$, siendo la temperatura optima en función a las descargas entre 18 y $20^{\circ} \mathrm{C}$.

La clorofila a por su parte osciló para la mayores descargas entre 1 y $2 \mathrm{mg} / \mathrm{m} 3$, pero el rango en el que se le pesco fue entre 0,5 y $2 \mathrm{mg} / \mathrm{m} 3$.

Podemos decir que es posible realizar el seguimiento de algunas pesquerías pelágicas a través de la combinación de algunos parámetros oceanográficos y el manejo de software de Sistemas de Información Geográfica

Palabra clave: Clorofila-A, Temperatura superficial del mar, ARC-GIS

\section{ABSTRACT}

In this work presents the results of the application of Geographic Information Systems (GIS) in the analysis of oceanographic variables: temperature and chlorophyll A, on the location of the fishing areas. It is used SOFTWARE ARC GIS 9.2, on which it has been put on top the layers of chlorophyll A and temperature catch by the artisanal vessels engaged in fishing for Humboldt squid.

The final results show us that there is a correlation between the location of the fishing areas and the distribution of sea surface temperature and also with the concentration of chlorophyll A. It was determined the location of temperature range between $16^{\circ}$ and $23^{\circ} \mathrm{C}$, being the optimum temperature according to discharges between $18^{\circ}$ and $20^{\circ} \mathrm{C}$.

Meanwhile, Chlorophyll A varies for greater shock ranged from 1 to $2 \mathrm{mg} / \mathrm{m} 3$ but the range in which it was fished it was between 0.5 and $2 \mathrm{mg} / \mathrm{m} 3$.

We can say that it is possible to monitor some deep-sea fisheries through the combination of some oceanographic parameters and software management of Geographic Information System.

Keyword: Chlorophyll-A, sea surface temperature, ARC-GIS

\footnotetext{
1 Ing. Juan Manuel Tume Ruiz. MSc. Docente UAP, Docente adscrito a la Facultad de Ingeniería Pesquera de la Universidad Nacional de Piura

2 Blgo. Ronald Marcial Ramos MSc. Docente adscrito a la Escuela de Biología de la Universidad Nacional de Piura
} 


\section{INTRODUCCIÓN}

La Pesca en la zona norte del Perú hasta la década de los 90 era sustentada por una especie que era objetivo de la embarcaciones arrastreras, esa especie era la merluza (Merluccius gayi peruanus); una especie que fue extraída en inmensas cantidades y que por el mal manejo del recurso terminó por colapsar. En esa misma década las descargas de otro recurso empiezan a repuntar especialmente en la pesca artesanal, Esta especie es la Pota (Docidicus gigas), La pota se caracteriza una especie semi-oceánica a diferencia de otras de la misma familia cuya distribución es transoceánica. Se han identificado tres grupos en base a la talla (longitud de manto): pequeña (130-340 mm), mediana $(240-600 \mathrm{~mm}$ ) y grande (mayor a 400 hasta 1000 mm o más). El crecimiento en todos estos grupos es rápido, estimándose el tiempo de vida en alrededor un año. Los más grandes especímenes pueden alcanzarlosdosaños devida. (IMARPE 2005)

Dada la importancia del recurso, la pesca de la pota ha revertido gran importancia sobre todo en las embarcaciones artesanales, entre el 2010 y 2011 el esfuerzo pesquero fue de 650 embarcaciones de la jurisdicción de Paita y Talara las dedicadas a la pesca de este recurso (IMARPE 2011), por tal motivo dada la competividad y las exigencias del mercado las embarcaciones se han adecuado a diferentes cambios tecnológicos. Dentro de estos cambios están el uso de equipos y nuevas tecnologías de búsqueda implementando equipos auxiliares como el sonar, el radar, el ecosonda. Pero estas tecnologías van quedando desfasadas dado que lo que se quiere en la actualidad es información en tiempo real, que permita ahorrar y que le de al pescador e investigador una herramienta en la pesquería de un recurso para el ordenamiento y la administración organizada de éste, implementando programas o planes de manejo donde el objetivo es preservar nuestros recursos hoy tan escasos.
En el presente trabajo se pretende implementar un sistema para identificar la ubicación de los cardúmenes tomando como base su hábitat en condiciones normales y especialmente en su distribución en función de las variables oceanográficas del mar sería importante para el desarrollo económico, técnico y para la adecuación de los planes de manejo de los recursos pesqueros.

\section{MATERIALES Y MÉTODOS}

\section{Zona de estudio}

La zona de estudio se enmarca en el Puerto de Paita donde se desarrolla la mayor actividad de descargas del recurso Pota Dosidicus gigas y también donde se ubica el $98 \%$ de plantas procesadoras de congelado de este recurso. La jurisdicción del Puerto de Paita está ubicada al Noroeste del Perú $81^{\circ} 07^{\prime} \mathrm{W}$ de longitud y $05^{\circ} 05^{\prime} \mathrm{S}$ de latitud. En la zona de estudio existen 16 zonas de desembarque, se estimó estadísticamente las zonas más importantes en función a las descargas anuales y se determinaron solo 5 de gran importancia donde se tomará la información respectiva.

\section{Información de captura}

La información de captura será tomada de los datos históricos reportados por el Instituto del Mar del Perú, entre los años 2010 y 2011. Pero además la información es tomada de las descargas diarias de las embarcaciones en 4 puntos específicos de desembarque, como se aprecia en la figura 01 estos 4 puntos son: Muelle Artesanal de Puerto Nuevo, Desembarcadero Pesquero Artesanal - Paita, Muelle de la Estación Naval, Muelle del Centro de Entrenamiento Pesquero - Paita. Los datos de desembarques de pota se analizaron y procesaron con el fin de discriminar alguna información que nos lleve al error. Ya que se hizo un seguimiento de las embarcaciones que descargaban en cada zona de descarga, donde el encargado hizo entrevistas a los patrones de pesca y a los tripulantes de las embarcaciones. 
Para la obtención de la información respectiva se utilizó una encuesta, en ella se trató de abarcar información básica para nuestro estudio como: Zonas de pesca en coordenadas geográficas, Profundidad de metros, de la zona de captura, Captura total, Tiempo de pesca, Otros datos.

\section{Observaciones a bordo}

Para las observaciones a bordo de las embarcaciones pesqueras, la frecuencia se estimó en dos embarques mensuales en tres embarcaciones escogidas al azar de la flota. con la finalidad de contrastar datos de temperatura y captura, para ello se capacitó a personal que realizó este trabajo. Las observaciones hechas a bordo fue tomada por personal capacitado quien tomó la información respectiva.

\section{Información satelital}

La información satelital es la tomada de la Dirección de Oceanografía y Sistema de Información
Geográfica del IMARPE (DIPDT - UPRSIG) la que obtiene la información satelital de la Administración Nacional Americana Oceánica y Atmosférica (NOAA). (Unidad de Percepción Remota y Sistema de Información Geográfica). Específicamente la información que se tomará será de las zonas de pesca más visitadas, área que se muestra en la figura 1 .

Las cartas de Temperatura Superficial del Mar (TSM) son elaboradas desde la imagen cruda recepcionada, a la cual se le somete a una calibración por el sistema y una rectificación geométrica.

Asimismo se utilizan las cartas de Clorofila a que han sido proveídos por la pagina Ocean color, de la nasa a través del siguiente enlace http://oceancolor.gsfc.nasa.gov/, de donde se bajó la información general se ingreso al programa Arc Gis 9.3, se georreferenció y se obtuvieron las cartas de clorofila a en la zona norte de Perú.

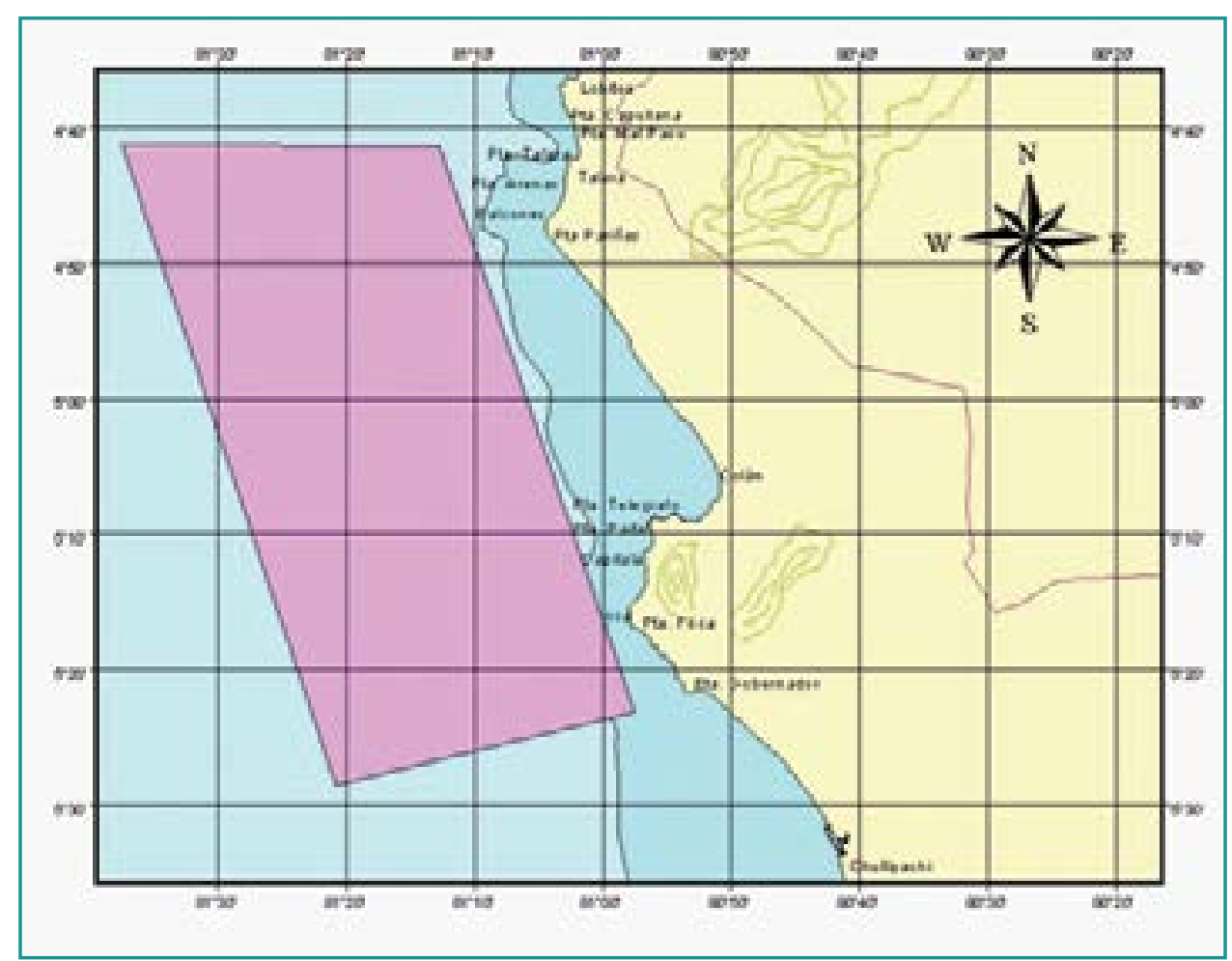

Figura 1: Ubicación de zonas de pesca y de cartas de parámetros oceanográficos a analizar durante el estudio 


\section{RESULTADOS}

\subsection{Características oceanográficas del mar} en la zona norte del Perú

\section{Temperatura superficial del mar peruano}

La temperatura de la superficie del mar es un parámetro relevante en el desarrollo de los sistemas biológicos y eventualmente puede usarse como trazador del dinamismo de la distribución espacial de las especies. A través de sensores como el AVHRR y MODIS se puede determinar este parámetro sinópticamente sobre grandes superficies de manera reiterada. Estas características confieren a este tipo de observaciones un valor incalculable para los estudios oceanográficos.

Sin embargo, la explotación adecuada de este potencial necesita de ciertas cualificaciones que permiten asignarles un nivel de significancia y de precisión.

Los datos usados en este trabajo son imágenes del sensor AVHRR (Advanced Very High Resolution Radiometer) del año 2010 y 2011 en formato level 1B (10 bits), obtenidas de la página web http://www.class.noaa.gov e imágenes Level 2 del sensor MODIS de la página web: http://oceancolor.gsfc.nasa.gov.

Todas las imágenes tienen una resolución especial de $1 \mathrm{~km}$. Para validar las temperaturas de satélite se han utilizado datos In situ de marzo 2010 a marzo del 2011. Estos datos han sido obtenidos de los embarques de personas debidamente entrenadas en las embarcaciones artesanales.

En la figura 2 apreciamos la relación entre la temperatura tomada por el satélite y la temperatura tomada in situ.

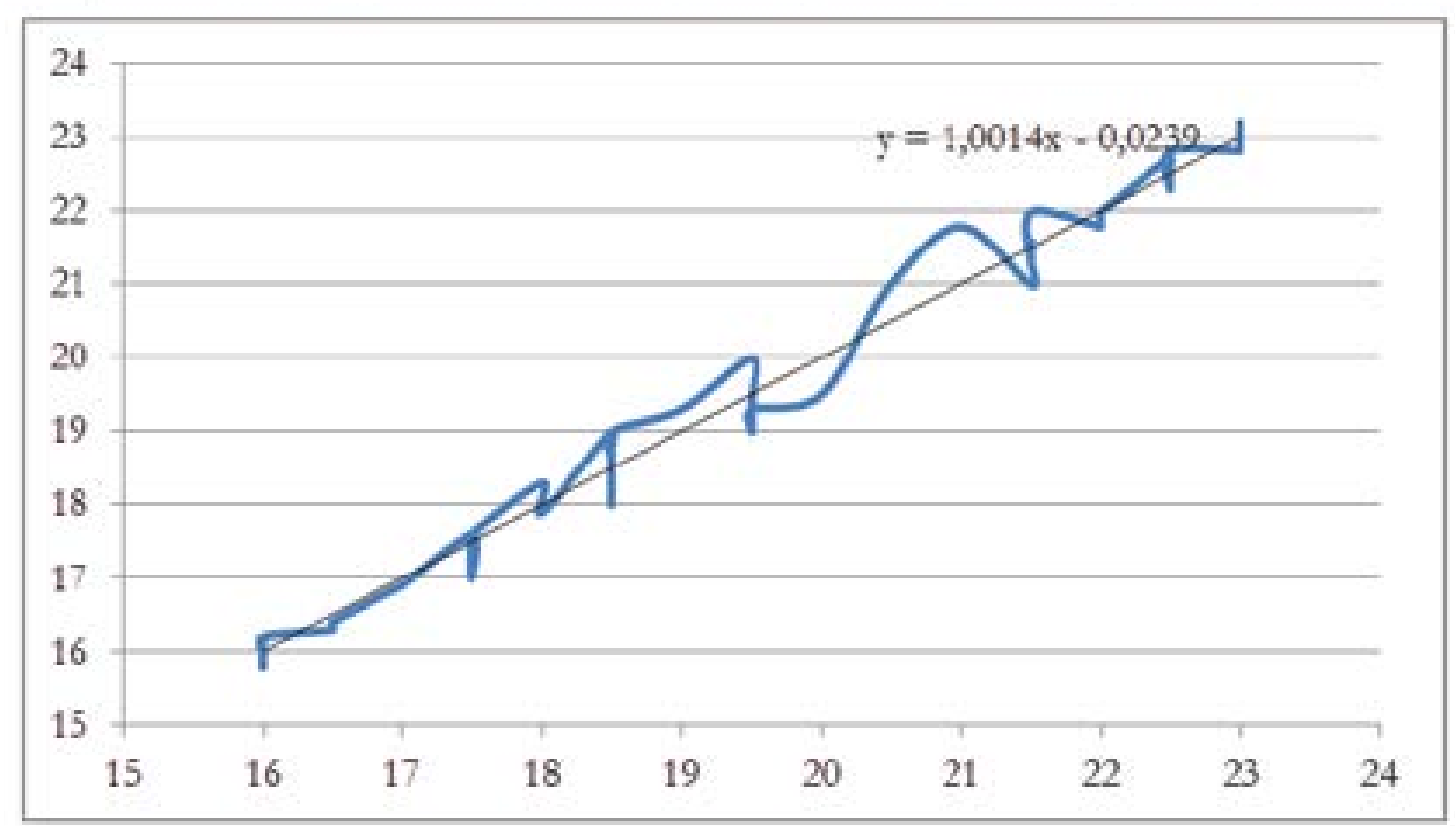

Figura 2. Relación entre la temperatura tomada de los satélites y la temperatura tomada en los embarques por faena de pesca

Se hizo el análisis estadístico de regresión lineal simple y se obtuvo la siguiente información la tabla 1 , donde se aprecia que la ecuación de regresión Tsat $=1.001$ Tinsitu +-0.024 , donde vemos que no hay una diferencia significativa ya que si aproximamos la ecuación podemos decir que Tsat $=$ Tinsitu. Para un valor de correlación $\mathrm{r}=1$. 
Tabla 1. Análisis de la Regresión lineal entre temperatura satelital y temperatura tomada insitu

\begin{tabular}{|c|c|c|c|c|c|c|c|c|}
\hline \multicolumn{9}{|c|}{ Coeficientes $^{a}$} \\
\hline & \multirow{4}{*}{ Modelo } & \multirow{2}{*}{\multicolumn{2}{|c|}{$\begin{array}{l}\text { Coeficientes no } \\
\text { estandarizados }\end{array}$}} & \multirow{2}{*}{$\begin{array}{l}\text { Coeficientes } \\
\text { tipificados }\end{array}$} & \multirow{4}{*}{$\mathrm{t}$} & \multirow{4}{*}{ Sig. } & \multirow{2}{*}{\multicolumn{2}{|c|}{$\begin{array}{c}\text { Intervalo de confianza } \\
\text { de } 95,0 \% \text { para B }\end{array}$}} \\
\hline & & & & & & & & \\
\hline & & $\mathrm{B}$ & Frror tín & Reta & & & Límite & Límite \\
\hline & & B & Error tip. & Beta & & & inferior & superior \\
\hline \multirow[t]{2}{*}{1} & (Constante) &,- 024 & ,394 & &,- 061 & ,952 &,- 817 &, 769 \\
\hline & T.SAT & 1,001 & ,020 & - & 49,901 & ,000 & ,961 & 1,042 \\
\hline
\end{tabular}

a. Variable dependiente: T.INSITU

Fuente: Elaborado con datos de campo y datos satelitales

Los resultados de las temperaturas, tiene predominancia una isoterma de $23^{\circ}$ frente a toda la costa norte. La temperatura aumenta a medida que se aleja de la costa y se orienta en dirección sureste.

En Abril, se observa que las isotermas se desplazan hacia el océano pero predominando aún la de $23^{\circ} \mathrm{C}$. En mayo las temperaturas altas alejan de la costa con respecto a Marzo, disminuyendo rotundamente especialmente en la segunda quincena desde $23^{\circ}$ hasta los $20^{\circ} \mathrm{C}$. En junio siguen disminuyendo hasta llegar una predominancia de $19^{\circ} \mathrm{C}$. En el mes de julio se alcanzan temperaturas más bajas respecto a junio llegando de $18^{\circ} \mathrm{C}$ en la primera quincena hasta $17^{\circ} \mathrm{C}$ en la segunda quincena. En agosto las temperaturas siguen bajando llegando a predominar la isoterma de $17^{\circ} \mathrm{C}$. En el mes de setiembre se alcanza la temperatura más baja del año es decir la temperatura de $16^{\circ} \mathrm{C}$. Octubre es un mes especialmente en la segunda quincena donde la temperatura aumenta hasta $17^{\circ} \mathrm{C}$, y en noviembre se logra una temperatura aun mayor predominando la isoterma de $18^{\circ} \mathrm{C}$.

En el mes de diciembre las temperaturas altas se acercan a las costas del norte del Perú y en la segunda semana la temperatura alcanzada es $20^{\circ} \mathrm{C}$.

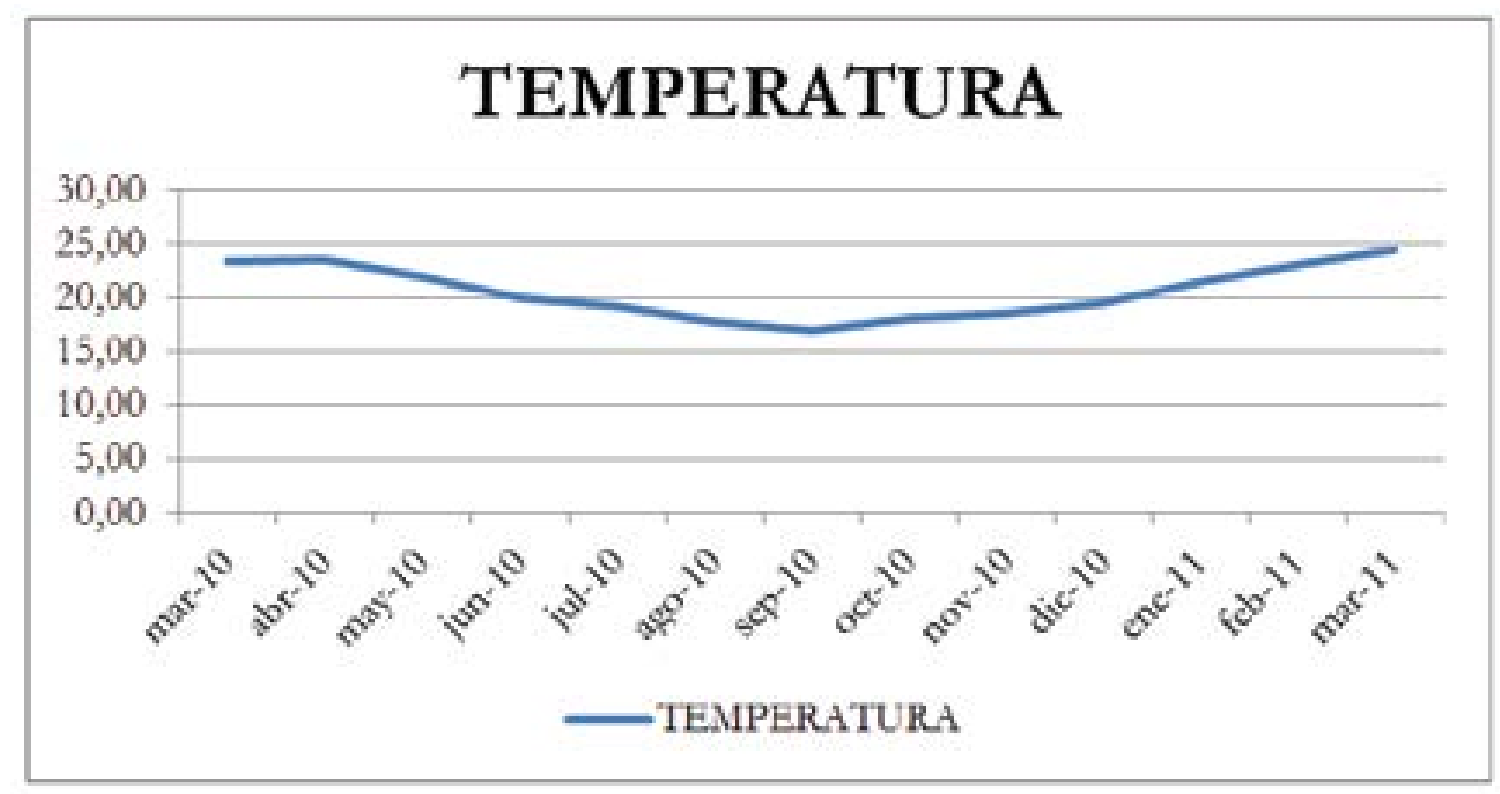

Figura 3: Temperaturas superficiales del mar entre marzo del 2010 y marzo del 2011 
En enero del 2011, sigue subiendo la temperatura y predomina la isoterma de $21^{\circ} \mathrm{C}$. En el mes de febrero la temperatura aumenta notablemente alcanzándose temperaturas de entre 22 y $24^{\circ} \mathrm{C}$. En el mes de marzo siguen predominando las temperaturas de 23 y $24^{\circ} \mathrm{C}$.

En la figura 3 vemos que la temperatura promedio más baja alcanzada en la época de estudio fue de $16^{\circ} \mathrm{C}$ en el mes de setiembre, la demás temperaturas están entre 19 y $23^{\circ}$, para los demás meses.

\subsubsection{Clorofila "a”}

Usamos la clorofila (el pigmento fotosintético de las plantas) como una medida del crecimiento biológico de los océanos. Las zonas azules son los desiertos del océano donde hay menos clorofila. Las zonas rojas y amarillas, normalmente cercanas a las costas, son las de mayor actividad biológica. Las cartas de Clorfila "a" según la información obtenida de sensores como el AVHRR y MODIS, lo que se aprecia hay una gran predominancia de concentraciones altas de clorofila "a" en la zona de estudio variando los valores desde 0,2 hasta $3,6 \mathrm{mg} / \mathrm{m} 3$, valores que indican la productividad primaria abundante en la zona de estudio. Mediante la información cartográfica del sensor, se determinó que en el mes de marzo tubo su valor máximo de 2,817 y su valor mínimo $1,701 \mathrm{mg} / \mathrm{m}^{3}$.

En abril los niveles de concentración subieron con un rango entre 2 y $3.6 \mathrm{mg} / \mathrm{m}^{3}$, en mayo se mantienen los valores, pero baja a fines de mes a valores cercanos a $1 \mathrm{mg} / \mathrm{m}^{3}$. En el mes de julio se repunta el valor recuperándose al valor $2 \mathrm{mg} / \mathrm{m}^{3}$, manteniendo ese valor aproximado hasta la primera semana de julio, entre julio y agosto el valor disminuyó rotundamente hasta $0,2 \mathrm{mg} / \mathrm{m}^{3}$. En setiembre y octubre se alcanzan los valores más altos de este parámetro, siendo esos valores entre 2 y $3 \mathrm{mg} / \mathrm{m}^{3}$
En noviembre los valores de Clorofila "a" siguen en aumento alcanzado valores de $3.6 \mathrm{mg} / \mathrm{m}^{3}$, manteniendo estos valores hasta el mes de enero del 2011,

En Febrero y marzo nuevamente los valores vuelven a subir a valores cercanos a $3 \mathrm{mg} / \mathrm{m}^{3}$.

En el gráfico 02 se aprecian los dos picos mas bajos alcanzados en agosto del 2010 y enero del 2011 y los dos picos más altos que se alcanzan en abril del 2010 y noviembre del 2011, notamos también que otro pico alto se aprecia a partir del mes de febrero aun en formación

\subsection{Zonas de Pesca del recurso pota}

Las zonas de pesca según la información satelital se han ubicado desde Punta Pariñas en la zona norte hasta la Isla Lobos de afuera, como se sabe la Pota (Docidicus gigas), es una especie semi oceánica y que durante los últimos años se viene distribuyendo a lo largo de toda la costa peruana habiendo reporte de capturas hasta el norte de Chile.

Según la información analizada entre marzo del 2010 y marzo del 2011, En los picos de desove en Verano y en invierno, aun soportando los rangos de temperaturas, se ha mantenido frente a las costas de la zona norte.

Las zonas de pesca recogidas con información cruzada de campo y reportes de los patrones de pesca de las embarcaciones artesanales, se lograron insertar al programa a través de una hoja Excel y se ubicaron con el programa Arc Gis 9.3

Como se puede apreciar las zonas de pesca entre el marzo del 2010 y marzo del 2011, se han ubicado durante el mes de marzo hasta junio del 2011 entre Punta Pariñas al norte y Punta Aguja al extremo sur con un ligero desplazamiento hacia la zona sur, en el mes de julio, esta especie se 
ha desplazado al sur llegando hasta la Isla lobos de tierra en el mes de Agosto, Entre los meses de setiembre y octubre la especie se dispersa hacia el océano y se extiende hasta frente a la Isla Lobos de Afuera. Las Capturas promedios como se aprecian en la tabla 2, tienen su máximo valor en el mes de abril y mayo del 2010 y sus valores empiezan a bajar a partir del mes julio de 4,5 tn aproximadamente, hasta el pico mas bajo en setiembre, pero luego repunta en el mes de octubre donde las descargas aumentan a 4 toneladas en promedio. Esto también se puede notar en la figura 4.

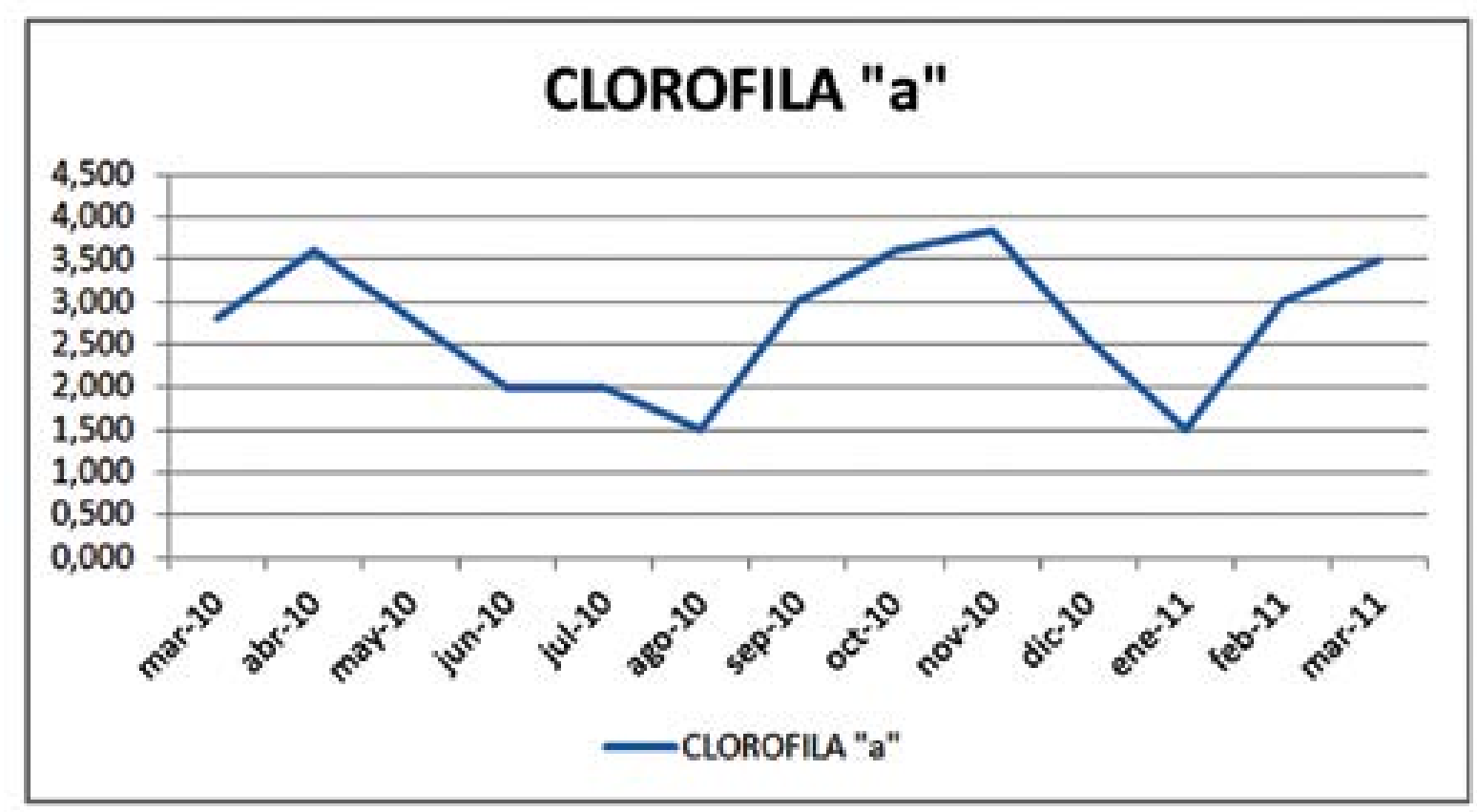

Figura 4: Clorofila "a" en el mar entre marzo del 2010 y marzo del 2011

Tabla 2: Capturas promedio mensuales de las embarcaciones artesanales entre marzo del $2010 \mathrm{y}$ marzo del 2011

\begin{tabular}{lc} 
MES & $\begin{array}{c}\text { CAPTURA PROMEDIO } \\
\text { (TONELADAS) }\end{array}$ \\
\hline MARZO & 8.171 \\
ABRIL & 17.447 \\
MAYO & 16.629 \\
JUNIO & 9.263 \\
JULIO & 4.440 \\
AGOSTO & 4.301 \\
SETIEMBRE & 2.962 \\
OCTUBRE & 4.032 \\
\hline NOVIEMBRE & 7.093 \\
DICIEMBRE & 7.041 \\
\hline ENERO 2011 & 10.416 \\
FEBERERO 2011 & 9.685 \\
MARZO 2011 & 7.778 \\
\hline
\end{tabular}




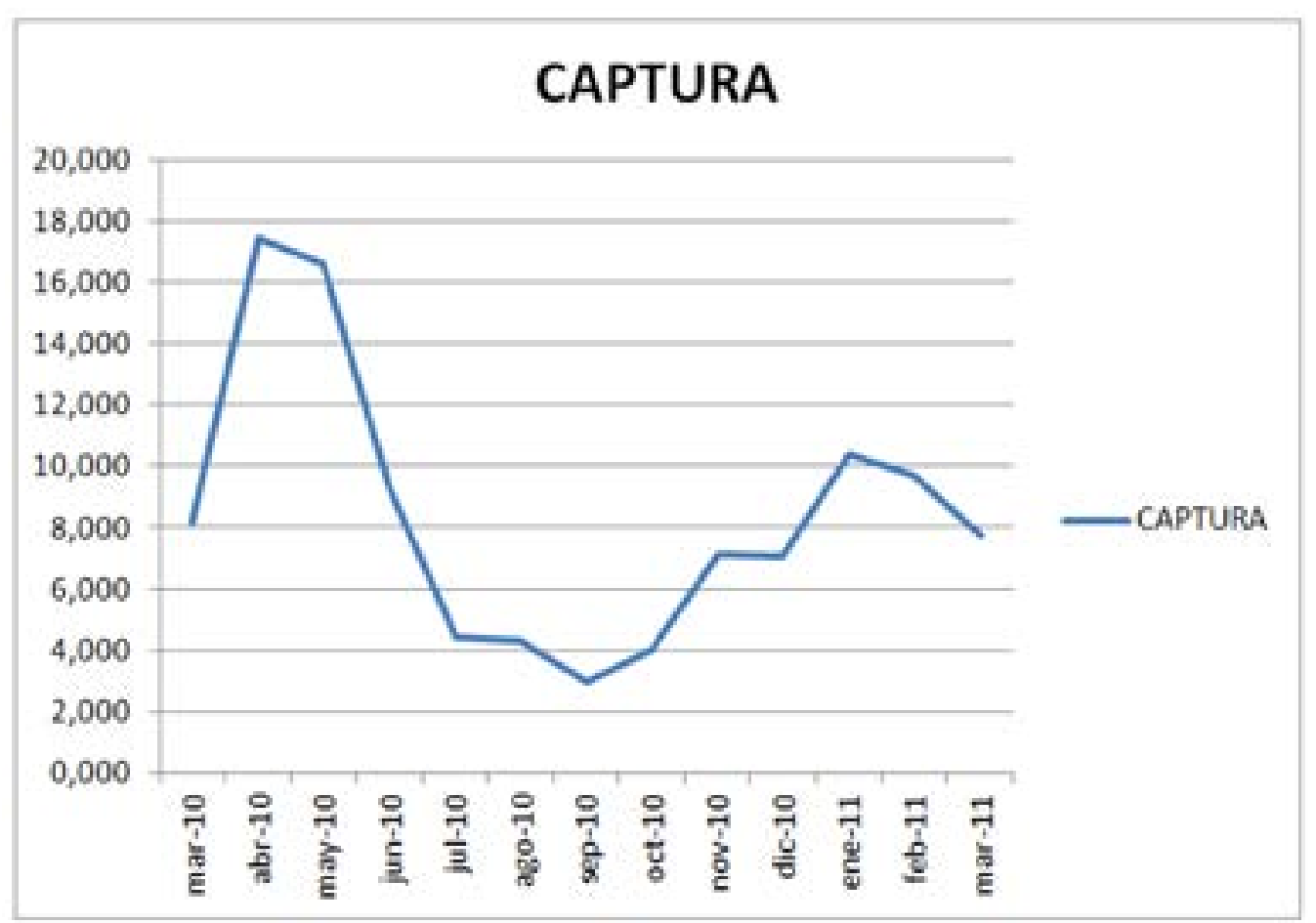

Figura 5. Distribución de las descargas mensuales de pota (Dosidicus gigas) entre marzo del 2010 y marzo del 2011

\section{DISCUSIÓN}

Los resultados presentados nos permiten decir que si existe una relación entre las zonas de pesca y las características oceanográficas analizadas, de tal manera que los datos de clorfila a y temperatura muy bien controlados pueden servir como un modelo que permita la ubicación de las zonas de pesca de pota (Dosidicus gigas). Agrupando la información mensual registrada por el estudio en estaciones, estos datos indican que: durante el otoño del 2010, la pota, se distribuyó entre Punta Pariñas y Punta Gobernador con temperaturas entre 21 y $23^{\circ} \mathrm{C}$, y los valores de clorofila estuvieron entre 1,5 y $2,2 \mathrm{mg} / \mathrm{m} 3$ como lo apreciamos en las figuras 6 al 8, los valores de temperatura para el mes de junio disminuyeron, esto aunado a la dispersión y profundización de la especie, quizás siguiendo la isoterma de $19^{\circ} \mathrm{C}$. Como se muestra en la figura 9.

La dispersión y profundidad puede deberse a distintos motivos y uno de ellos es la presencia de temperaturas de aguas sub superficiales cálidas o por la presencia de pequeños pelágicos como lo encontró Brito L.1996, quien manifiesta que la captura de pota se realiza cuando las temperaturas superficiales oscilan entre $17.0^{\circ} \mathrm{C}$ y $29.9^{\circ} \mathrm{C}$. Las menores temperaturas de estos intervalos posiblemente estén relacionadas con la migración estacional de especies de pelágicos menores (sardinas, macarelas y anchovetas), principalmente hacia las zonas de surgencias, puesto que gracias a la aportación de nutrientes provenientes de aguas más profundas y frías se crean condiciones óptimas para el crecimiento de juveniles y adultos (Mann y Lazier, 1996).

En nuestro estudio la profundidad de captura no se han tomado en cuenta pero sería importante que para estudios posteriores se analicen. Por su parte la variable presencia de juveniles se analiza por las zonas de surgencia con los valores de clorofila a. En el invierno notamos que la pota se dispersa notoriamente (Figuras 10 al 13) buscando alimentación y su temperatura optima, 
profundizándose especialmente en los primeros meses, las temperatura superficiales estuvieron entre 16 y $19^{\circ} \mathrm{C}$, y los valores de clorofila a variaron entre 0,5 y $1 \mathrm{mg} / \mathrm{m} 3$, podemos decir que si las temperaturas bajan,y los valores de captura también bajan esto debido a que el recurso no es asequible por las grandes profundidades que logra alcanzar que en algunos casos mostraron profundidades de hasta $80 \mathrm{~m}$.

Durante la primavera, el recurso pota nuevamente se empieza a concentrar frente a Paita y distribuyéndose hasta Punta Aguja en el sur, se estima que esta concentración en la zona es por el aumento de la temperatura especialmente a fines del mes de Diciembre, y respecto a la clorfila a los valores estuvieron en aumento desde 0,5 en setiembre hasta $1,5 \mathrm{mg} / \mathrm{m} 3$, aquí se evidencian que le especie se agrupa quizás debido que alcanza en Primavera un pico de desove donde la pota tiende a crear cardúmenes compactos, como lo estudió Carbajal W, (2009).

En verano cuando los valores de temperatura llegan (Figuras 14 al 17) desde $18^{\circ} \mathrm{C}$ en diciembre hasta $23^{\circ} \mathrm{C}$ en marzo del 2011 , la pota se concentra aun más frente a Paita.

La especie en los meses de verano nuevamente tienen un pico de desove, lo que hace que las capturas también tengan un pico de captura elevado, esto nuevamente debido a la presencia de cardúmenes compactos debido al agrupamiento de la especie para el desove.
Figura 6. Distribución de la pota en función a la temperatura y clorofila a marzo 2010

Figura 7. Distribución de la pota en función a la temperatura y clorofila a abril 2010
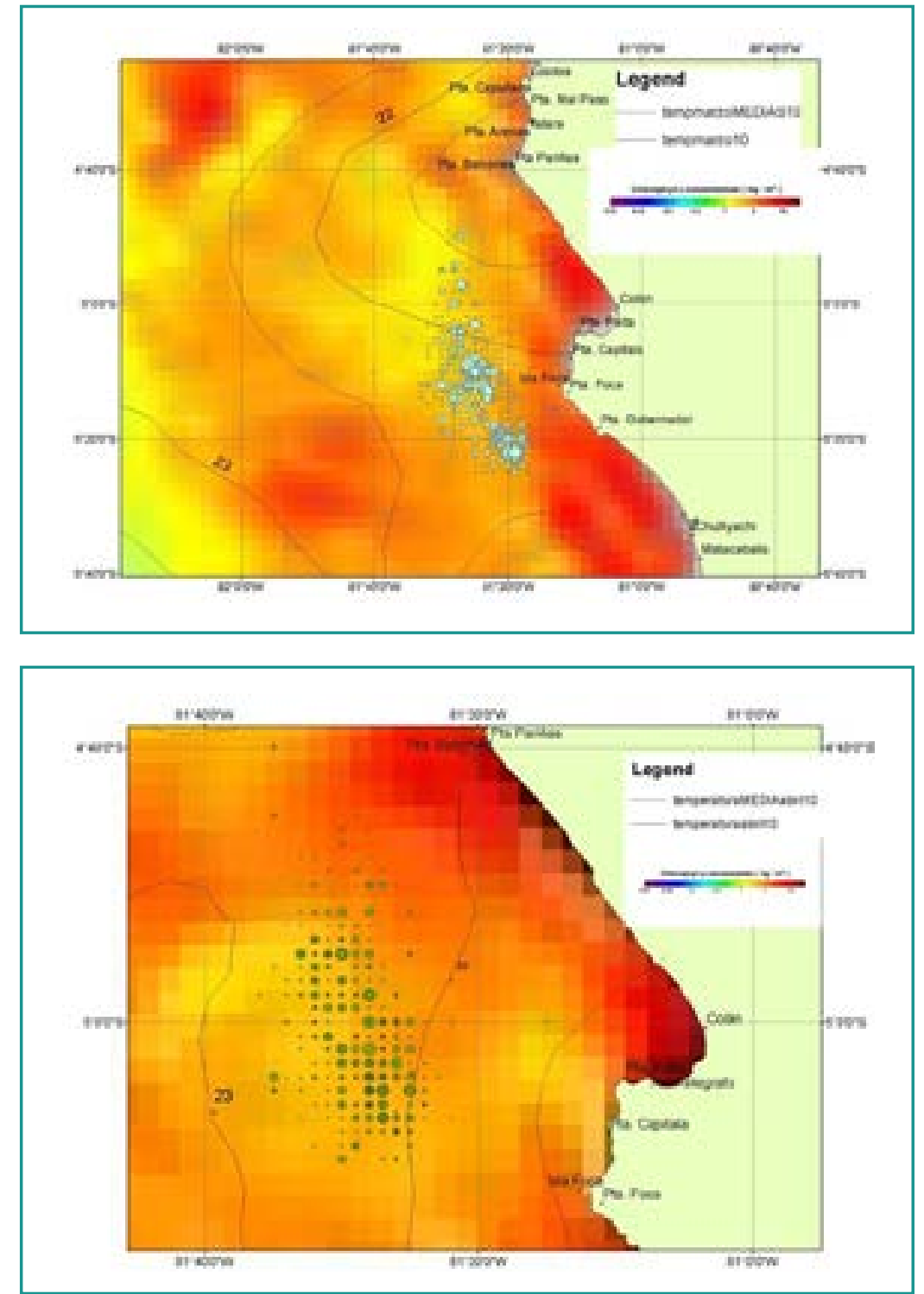

Ciencia y Desarrollo 16 (2), julio-diciembre 2013. 25:39 
Figura 8. Distribución de la pota en función a la temperatura y clorofila a mayo 2010

Figura 9. Distribución de la pota en función a la temperatura y clorofila a junio 2010

Figura 10. Distribución de la pota en función a la temperatura y clorofila a julio 2010
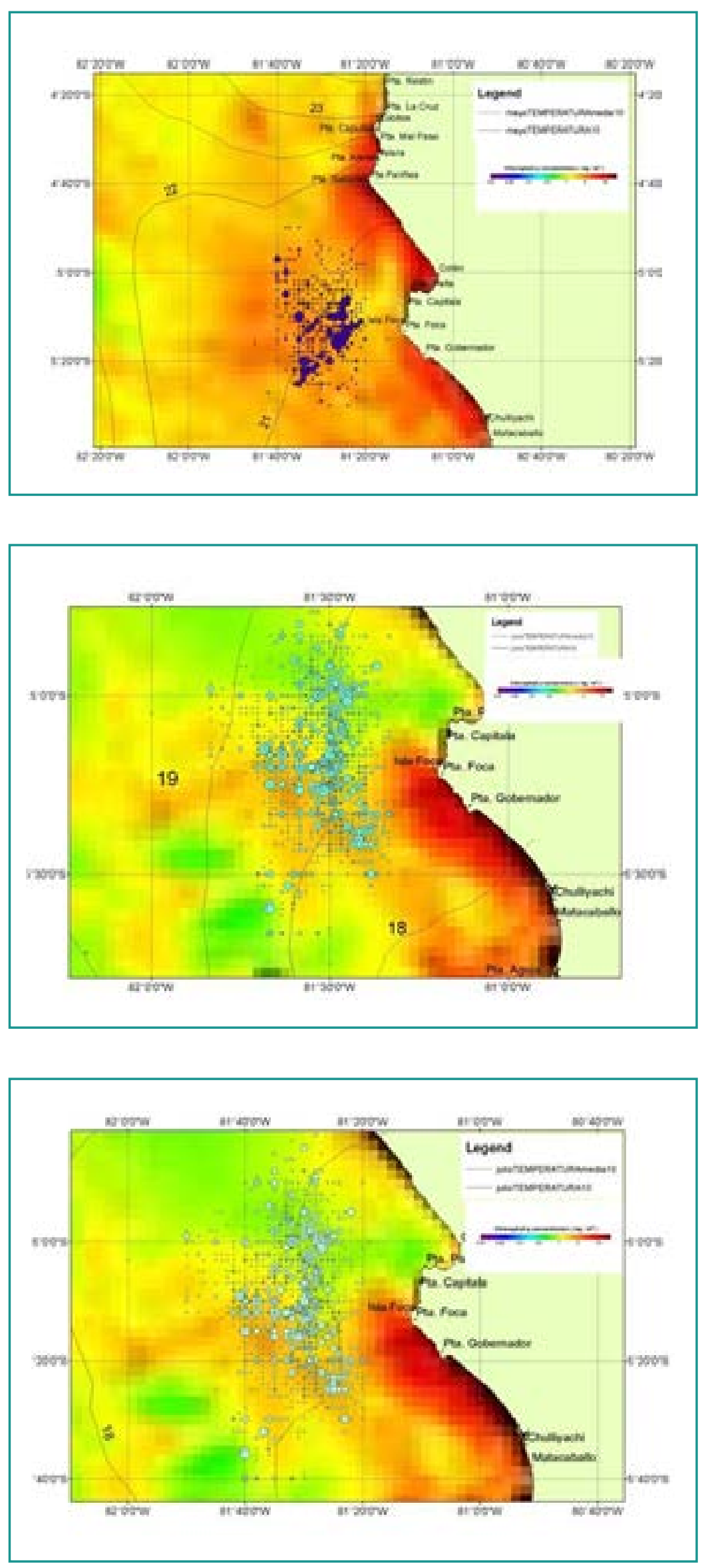
Figura 11. Distribución de la pota en función a la temperatura y clorofila a agosto 2010

Figura 12. Distribución de la pota en función a la temperatura y clorofila a setiembre 2010

Figura 13. Distribución de la pota en función a la temperatura y clorofila a octubre 2010
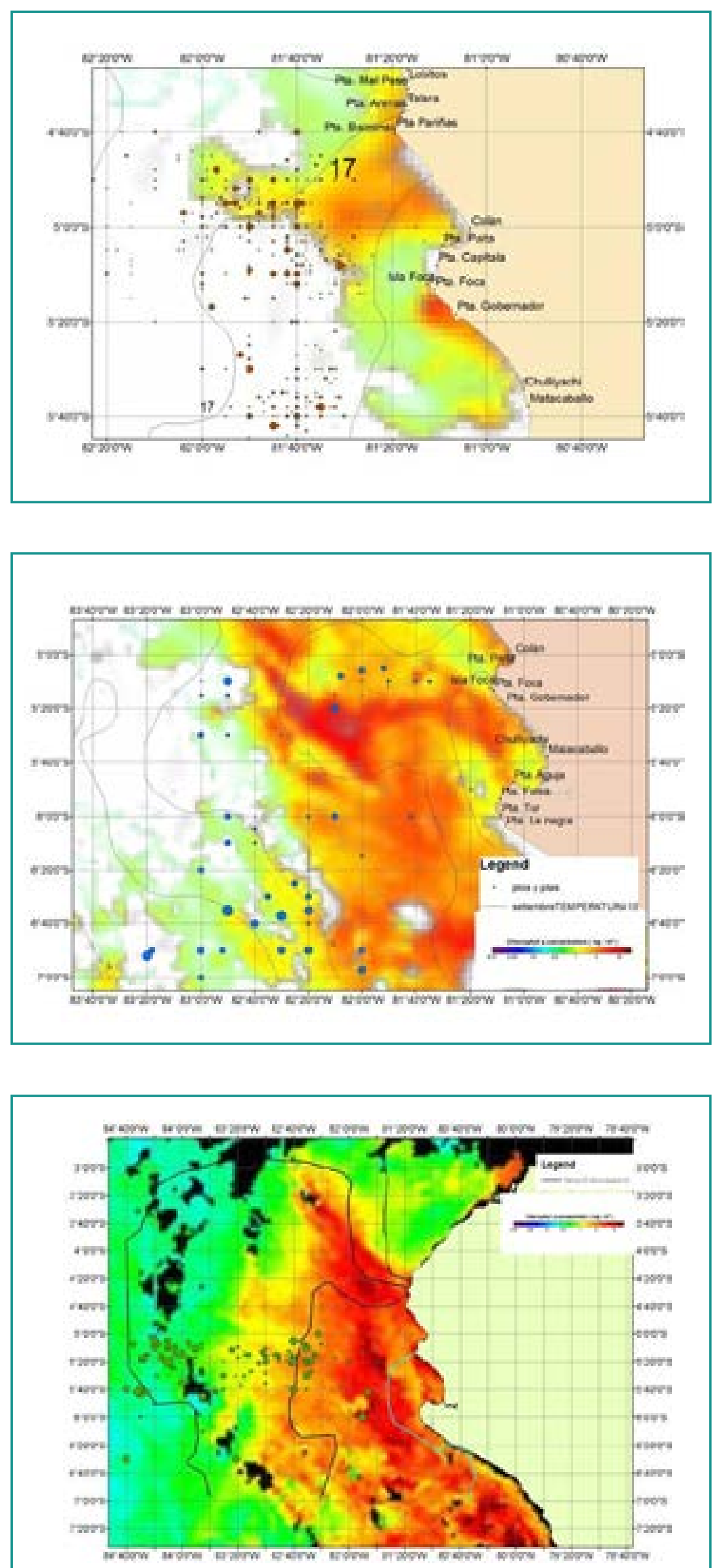
Figura 14. Distribución de la pota en función a la temperatura y clorofila a noviembre 2010

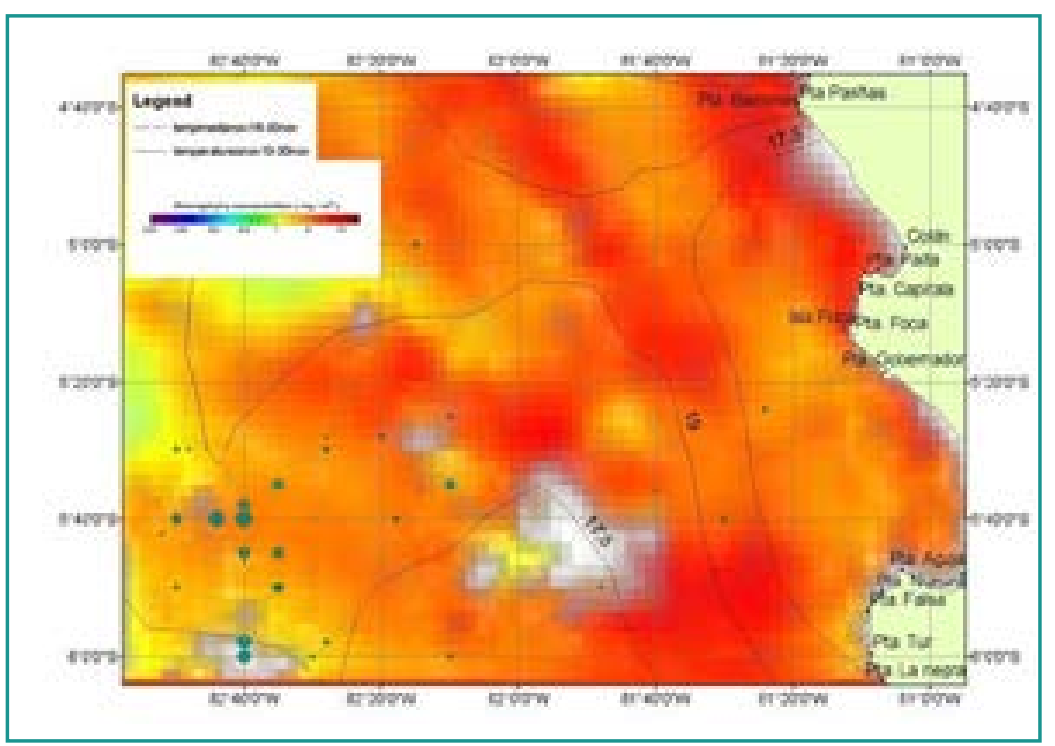

Figura 15. Distribución de la pota en función a la temperatura y clorofila a diciembre 2010

Figura 16. Distribución de la pota en función a la temperatura y clorofila a enero 2010
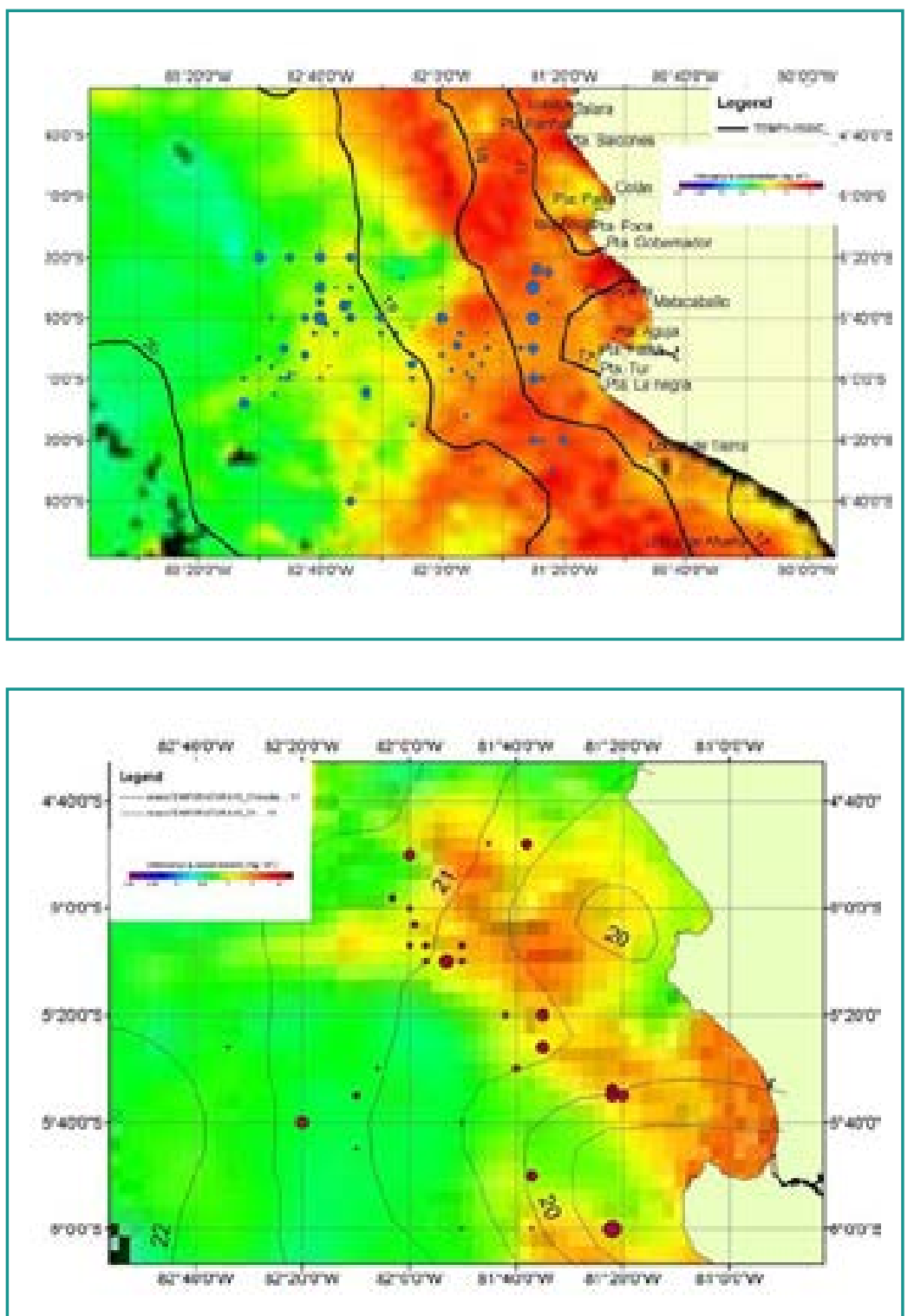
Figura 17. Distribución de la pota en función a la temperatura y clorofila a febrero 2010

Figura 18. Distribución de la pota en función a la temperatura y clorofila a marzo 2011
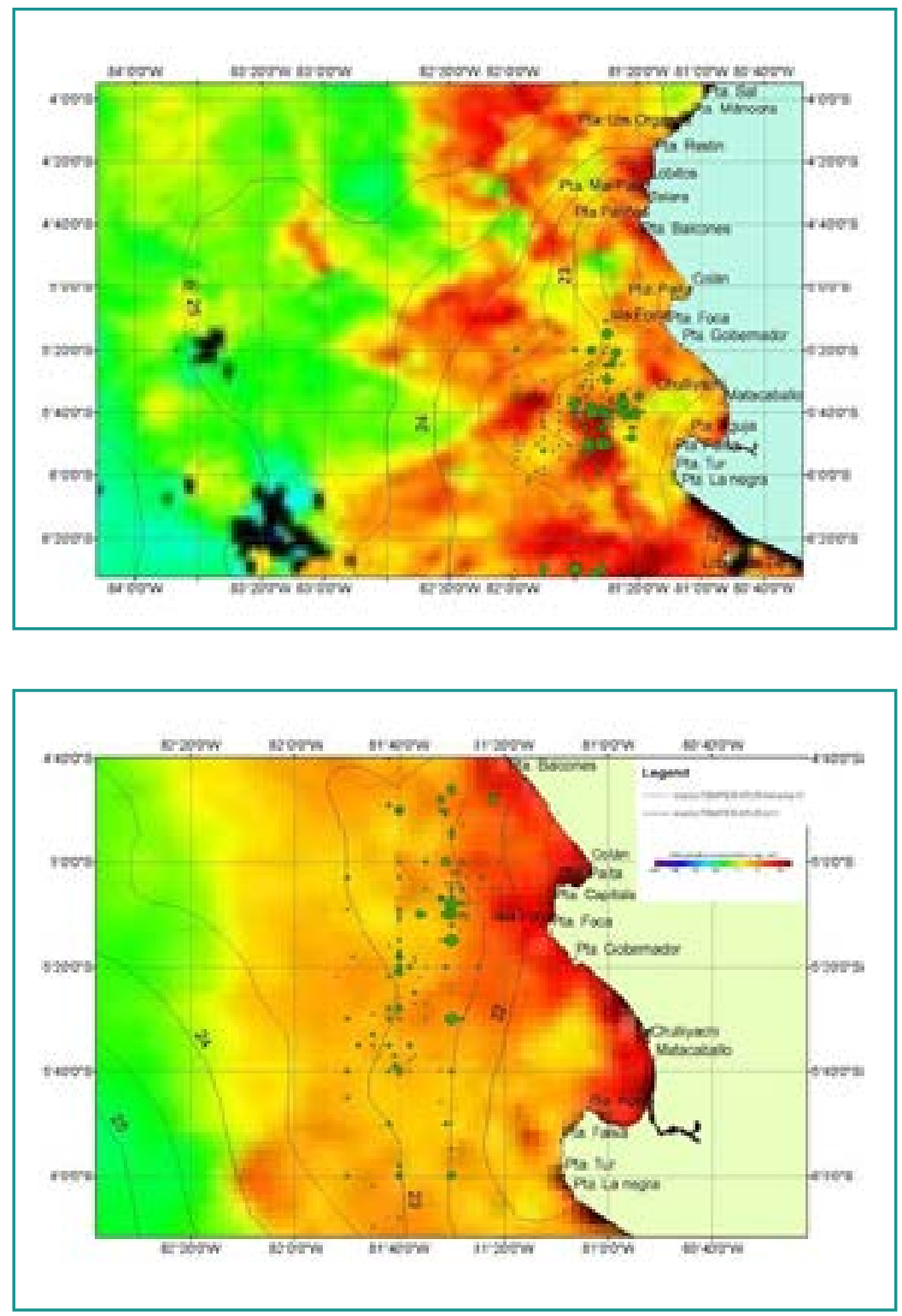
Tabla 3. Distribución de la Temperatura y la Clorfila a entre los meses de marzo 2010 y marzo 2011

\begin{tabular}{rrrrr} 
& \multicolumn{2}{c}{ TEMPERATURA } & \multicolumn{2}{c}{ CLOROFILA } \\
\multicolumn{1}{l}{ MESES } & \multicolumn{1}{c}{ MIN } & \multicolumn{1}{c}{ MAX } & \multicolumn{1}{c}{ MIN } & MAX \\
& ${ }^{\circ} \mathrm{C}$ & \multicolumn{1}{c}{${ }^{\circ} \mathrm{C}$} & $\mathrm{mg} / \mathrm{m} 3$ & $\mathrm{mg} / \mathrm{m} 3$ \\
\hline mar-10 & 22 & 23 & 1.5 & 2 \\
\hline abr-10 & 22 & 23 & 1.5 & 2 \\
\hline may-10 & 21 & 22 & 2 & 2.2 \\
\hline jun-10 & 18 & 19 & 1 & 0.5 \\
\hline jul-10 & 17.5 & 18 & 1 & 0.5 \\
\hline ago-10 & 16 & 18 & 1 & 0.5 \\
\hline sep-10 & 16 & 19 & 1.5 & 0.5 \\
\hline oct-10 & 17 & 18 & 1.5 & 1 \\
\hline nov-10 & 17.5 & 18.5 & 1.5 & 1 \\
\hline dic-10 & 18 & 19.5 & 1.5 & 1 \\
\hline ene-11 & 20 & 21 & 1.5 & 2.5 \\
\hline feb-11 & 22 & 23 & 3 & 4 \\
\hline mar-11 & 22 & 23 & 3 & 2.5 \\
\hline PROMEDIO & 19.77 & & 1.60 & \\
\hline MAXIMO & 23 & & 4 & \\
\hline MINIMO & 16 & & 0.5 & \\
\hline
\end{tabular}

\section{CONCLUSIONES}

La información satelital de temperatura superficial del mar y de clorofila a aplicado a los SIG, permiten establecer el modelamiento para el seguimiento de los cardúmenes de pesca del recurso Pota Dosidicus gigas (Orbigny 1835)

La pota se distribuyó ampliamente a temperaturas superficiales entre 16 y $23^{\circ} \mathrm{C}$, pero esto se debió a que cunado las temperaturas superficiales bajaban, la especie se profundizaba siguiendo la isoterma de $19^{\circ} \mathrm{C}$.

La pota durante la época de estudio (marzo del 2010 y marzo del 2011), se distribuyó entre Pun- ta Pariñas y Punta Aguja, teniendo como temperaturas optimas en el intervalo de 18 y $20^{\circ} \mathrm{C}$ y las concentraciones de Clorofila a entre 1 y $2 \mathrm{mg} / \mathrm{m}^{3}$

La distribución de la pota en el norte del Perú estudiada mediante los sistemas de información Geográfica permite elaborar modelos que puedan con información de temperatura y clorofila a en tiempo real vía satelital determinar las posibles zonas de pesca del recurso.

Las Capturas de pota tienen tres picos el primero en la primavera que coincide con su desove y el segundo cuyas capturas altas son más largas en el tiempo y que coincide con el pico de desove de verano. 


\section{REFERENCIAS BIBLIOGRÁFICAS}

- Armstrong, R., 1983, Marine environments of Puerto Rico and the Virgin Islands: automated mapping and inventory using LANDSAT data. Caribbean Fishery Management Council, 37 p.

- Bakun, A. y Csirke, J. 1998. Environmental processes and recruitment variability. In P.G. Rodhouse, E.G. Dawe y R.K. O’Dor (eds). Squid recruitment dynamics. The genus Illex as a model. The commercial Illex species. Influences on variability. FAO Fisheries Technical Paper, No. 376. Rome, FAO, 273 pp.

- Caddy, J. y Rodhouse, P. 1998. Do recent trends in cephalopod and groundfish landings indicate widespread ecological change in global fisheries. Rev. fish Biol. Fish. , 8: 431-444

- Caraux, D. and Austin R., 1983, Delineation of seasonal changes of chlorophyll frontal boundaries in Mediterranean coastal waters with NIMBUS- 7 coastal zone colour scanner data. $\underline{\mathrm{Re}-}$ mote Sensing Environ., 13(3):239-49

- Cornillon, P. 1986, Sea surface temperature charts for the southern New England fishing community. Marine Technology Society Journal, 20(2):57-65

- Cram, D., 1979, A role for the NIMBUS-9 coastal zone colour scanner in the management of a pelagic fishery. Fish.Bull./Vissèrij-Bull.,Cape Town, (11):1-9

- Elliott R., Gonzáles B. y Ramírez Q. 2003. Bancos naturales de invertebrados en Hornillos y El Colorado (Huacho- Región Lima). Instituto del mar del Perú Laboratorio Costero de Huacho 